83

\section{SUBARACHNOID SPACE QUANTIFICATION AS A SURROGATE MARKER OF BRAIN TISSUE INTEGRITY IN PRETERM INFANTS}

G. Lodygensky ${ }^{1}$, R. Recker ${ }^{2}$, A. Merglen², M. Benders ${ }^{3}$, F. Lazeyras ${ }^{4}$, P.S. Hüppi ${ }^{5}$

${ }^{1}$ Pediatrics, NICU, ${ }^{2}$ Pediatrics, University of Geneva, Geneva, Switzerland, ${ }^{3}$ Neonatology, Wilhelmina Children's Hospital, UMC Utrecht, Utrecht, The Netherlands, ${ }^{4}$ Radiology, ${ }^{5}$ Pediatris, Division of Development and Growth, University of Geneva, Geneva, Switzerland

Background: Clinicians when evaluating MRI of preterm infants are in need for simple measurements thatreflectactual brain tissue volumes. Subarachnoid space (SAS) measurement might be a reflection of white and grey matter integrity.

Methods: A cohort of 43 preterm infants was imaged at term equivalent by MRI (gestational age $29 \pm 2$ wks, birth weight $1295 \pm 460 \mathrm{~g}$ ). SAS was measured on a single T2-weighted coronal section at the level of the basilar truncus. SAS was then compared to actual brain tissue volumes quantified by the knn-algorithm using the same MRI.

Results: SAS correlated significantly with cerebrospinal fluid volume quantification (Pearson correlation $0.595, p<0.001$ ) but not with cortical grey matter, cerebral white matter or basal ganglia quantification.

Conclusion: SAS can't be used as a surrogate marker of brain tissue integrity.

\section{4}

PROLONGED VENTILATION CAUSES P27 KIP1 INDUCED CELL CYCLE ARREST IN NEWBORN RAT LUNG

\author{
A.A. Kroon ${ }^{1,2}$, J. Wang ${ }^{2}$, Z. Huang ${ }^{2}$, \\ M. Kuliszewski ${ }^{2}$, M. Post $^{2}$
}

${ }^{1}$ Pediatrics, Erasmus MC - Sophia Children's Hospital, Rotterdam, The Netherlands, '2Lung Biology Research, Physiology and Experimental Medicine Program, Hospital for Sick Children, Toronto, ON, Canada

Background: In vitro studies have demonstrated that mechanical stretch can inhibit lung cell proliferation. This inhibition of cell growth may lead to reduction of alveolar formation and contribute to the development of bronchopulmonary dyplasia.
Objective: To determine the effect of prolonged mechanical ventilation on cell-cycle regulation in a newborn rat model.

Methods: 7-day old Wistar rats were ventilated with low/moderate tidal volume and room air for $24 \mathrm{~h}$. Following ventilation arterial blood gas analysis was performed and the animal was killed. Lung tissues were processed for histological or molecular/protein analysis to determine (1) number of proliferating cells by BrdU and phospho-Histone $\mathrm{H} 3$ staining and (2) gene and protein expression of cell cycle regulatory proteins by real-time PCR and Western blotting.

Results: After $24 \mathrm{~h}$ of ventilation arterial blood gas values were within normal range but alveolar formation was reduced. The number of proliferating cells was decreased (BrdU incorporation decreased from 10 to $3 \%$ and phospho-histone H3 positive cells from 0.8 to $0.1 \%$. Expression of CyclinD1 and E1 mRNA and protein was markedly downregulated. Instead, protein expression of the CDK inhibitor p27 Kip1 was significantly increased while its phosphorylation at site T157, T198 and T187 was decreased. Interestingly, CDK inhibitor p16 1 nk4a levels were decreased by ventilation .

Conclusions: Prolonged mechanical ventilation causes cycle arrest of lung cells in newborn rats by increased transcription and nuclear localization of the CDK inhibitor p2 $7^{\text {Kip } 1}$ These data may in part explain the arrest in alveolarization by mechanical ventilation of the neonatal lung.

\section{5}

\section{BULLYNG IN SCHOOLS - BELGRADE}

\section{S. Tomic}

Haelth Centar Savski Venac, Belgrade, Serbia

Introduction: Contemporary world happenings followed by the financial and social crisis have resulted the increase of misery and poverty at the majority of the population, and especially of the most vulnerable groups as children - the young. All this together resulted the identity crisis, the value disarrangement that led to various types of battery and neglect and led to other forms of risky behavior. We witness every day the increase of all kinds of mistreating and especially of the bullying among the young. The aim is always the same - to hurt the victim. 